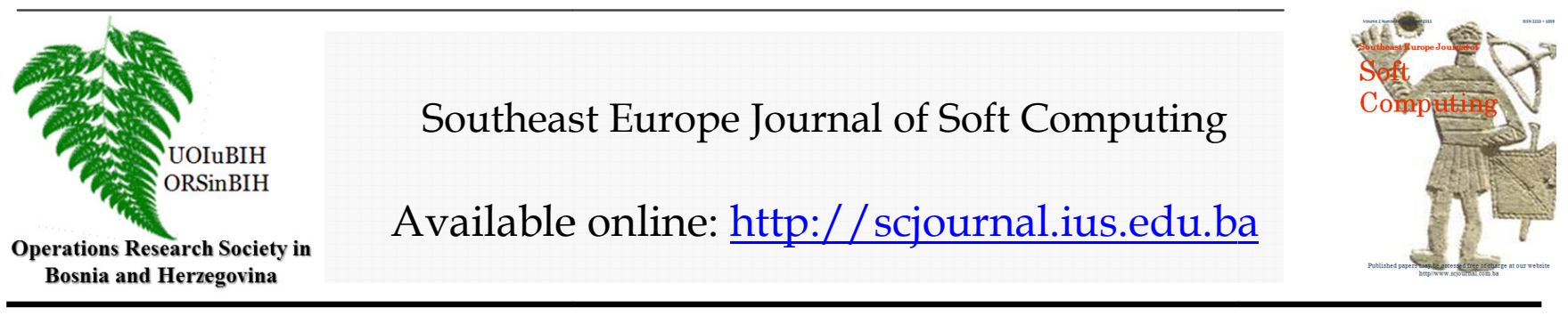

\title{
A Literature Survey on Reverse Logistics of End of Life Vehicles
}

\author{
Emine Cin ${ }^{\mathrm{a}}$, Ali Osman Kuşakcı ${ }^{\mathrm{b}}$ \\ a,b Istanbul Commerce University, Graduate School of Natural and Applied Sciences, Küçükyalı E5 \\ KavşağıInönü Cad. No: 4, Maltepe 34840, Istanbul, Turkey \\ aeminecinn@gmail.com, ${ }^{\text {a }}$ aokusakci@ticaret.edu.tr
}

Article Info

Article history:

Article received on 8 Jan. 2017

Received in revised form 18 Mar. 2017

Keywords:

End-Of-Life Vehicles, Reverse

Logistics, ELV

\begin{abstract}
Today, recycling of used products and materials has become an increasingly important sector. Mankind, who uses the natural resources unconsciously, has found ways to improve recycling techniques when they realized that resources are becoming increasingly depleted. In the automotive sector, which is one of the largest sectors in the world, natural resources are being used to a great extent. According to the statistics, in 2009, approximately 9 million end-of-life vehicles (ELV) in Europe were withdrawn from traffic. Undoubtedly, this figure shows the necessity and importance of designing reverse logistics network optimized for ELVs. This research aims to determine the gaps in the literature by examining the studies made from the past to the present day in the field of reverse logistic network design for vehicles that have completed their life cycle. In this article, the studies in the fieldare analyzed based on objective functions, decision variables, constraint handling metod, optimization methods used. Considered studies in this work are clustered using a special artificial neural network tool, SelfOrganizing Maps (SOM), and the frequencies of the characteristics are shown in the study. This study, which includes a review of the literature and a clustering of studies, aims to guidethe researchers working on the design of rreverse logistics networks for ELVs.
\end{abstract}

\section{INTRODUCTION}

The recycling sector, aims to provide economic and ecological benefits with less material and resource consumption, has become a market of 5 billion Euros with the contributions of both private sector and local governments. It aims to prevent the rapid depletion of natural resources through recycling, which is seen as a mean of efficient economic investment in the long term, and to transform the produced waste into an input and value for the economy. Future production and consumption models are being redesigned in order not to create any waste and to recycle the generated wastes as much as possible. For this purpose, there is a great need for reverse logistics networks that optimize the whole system which is necessary for collecting, separating, storing, transporting and bringing the new product to the economy with minimum cost.

Recycling in the automotive sector, which is one of the locomotive sectors of the world economy, is at the forefront of issues that need to be taken seriously. Unfortunately, millions of tons of vehicles completed their economic life each year, are turning into nature as waste and incurring irreversible damage to nature.

In this article, the scientific studies conducted from the past on the design of the ELV logistics networks will be studied and examined in detail. The studies taken into consideration will be clustered by self-organizing maps 
method (SOM) which is a special kind of artificial neural networks considering variaous features such as "network structure", "optimization model", "objective function", "method to handle uncertainty", and "solution approach". As a result of the clustering process, it will be determined which areas are studied intensively and in which areas there are gaps for more dedicated research in the literature.

This work is organized as follows: the current section is the first section whereas the second part of the article will separately include the clustering analysis, SOM, and the results of the clustering. In the third part; the related works will be evaluated in detail, and in the fourth part, the results will be given.

\section{METHODOLOGY}

\subsection{Clustering Analysis}

Clustering analysis is a method of classifying the units in a research by gathering them within certain number of groups according to similarities, and revealing the common characteristics of the units and making general definitions about these classes[1]. There are different approaches according to the user's purpose and usage area. Some of these methods are $\mathrm{K}$ average methods [2], fuzzy c-mean methods [3], and SOM[4].

\subsection{Self Organizing Maps (SOM)}

SOMs are a special type of artificial neural networks used for data clustering and representation. The technique was developed by TeuvoKohonen in 1982, it is also called Kohonen networks [4].

If the number of groups are unknown, a SOM performs unsupervised learning because there is no output variable to be estimated [5].

A SOM consists of an input layer and a two-dimensional Kohonen layer[6]. The nodes in the input layer are the variables (or properties) of the input data while the nodes in the output layer, also those are known as the Kohonen layers, represent clusters. The output layer has usually two dimensions. The structure consisting of rows and columns is in the form of a grid [7].

Unlike other artificial neural networks in Kohonen networks, the alignment of neurons in the output layer is very important. This sequence can be linear, rectangular, hexagonal or cubic. Rectangular and hexagonal arrangements are mostly preferred.

Assuming that there are $m$ number of variables, and $n$ number of nodes (clusters), the distance of each pairs of nodes is considered. In order to construct clusters, the distance between the weight vector (w) and the input vector (x) for each node can be calculated as shown in Equation 1 using Euclidean distance [8][9]. In equation (1), iis the input, and $\mathrm{j}$ is the index representing the variable considered.

$$
d_{i}=\sqrt{\sum_{j=1}^{m}\left(x_{j}-w_{i j}\right)^{2}}(1)
$$

The main steps of SOM are given in Table 1:

Table 1: Steps to Self-Organizing Maps

\begin{tabular}{|l|l|}
\hline Step 1: & $\begin{array}{l}\text { In the first step, the weight vector is given random } \\
\text { initial values between } 0 \text { and } 1 .\end{array}$ \\
\hline Step 2: & $\begin{array}{l}\text { The distance between each input and the weight } \\
\text { vector is calculated with the help of Equation } 1 .\end{array}$ \\
\hline Step 3: & $\begin{array}{l}\text { The input (neuron) having the smallest distance } \\
\text { between the calculated distances is selected. The } \\
\text { selected input is called the winner node. }\end{array}$ \\
\hline Step 4: & $\begin{array}{l}\text { With the winning node and learning parameter }(\alpha), \\
\text { weights are updated using the following formula.It } \\
\text { is assumed that the learning parameter } \alpha \text { has a } \\
\text { value between 0 and 1, which is assumed to have a } \\
\text { value, usually closer to 0 (Alpaydin, 1998). }\end{array}$ \\
$\begin{array}{l}w_{j} \text { (new) }=w_{j} \text { (current) }+\alpha\left[x-w_{j}(\text { current)] }\right. \\
\text { Step 5: }\end{array}$ & $\begin{array}{l}\text { Step 3 and Step 4 are repeated until the stopping } \\
\text { criterion }\end{array}$ \\
\hline
\end{tabular}

In the training process of SOM, neurons are in competition with each other. At the end of the competition process, the winning neurons and surrounding neurons; Their weights are being renewed according to the observations presented [10]. At the end of the training process, similar patterns will be represented in the same neurons or in neighboring neurons with small differences [11].

Categorical values are variables and features that need to be adapted to the data set for SOM application. The categorical property is transformed into new features as many as different values it contains, and new features take 0-1 binary values [12].

SOM can reduce a multidimensional dataset to two dimensions. This allows the entire data set to be easily evaluated by decision makers [13].

After clustering results are obtained from clustering algorithms, it is very important to verify that the results represent the actual structure of the data. Different cluster validity indices are used to evaluate the suitability of the cluster divisions obtained from the clustering algorithm. The Dunn index (DI) is only one of these [14].

The Dunn Index is used to find the optimal clustering which is calculated as given in Equation 2.

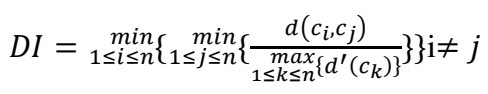

where DI is the distance between $\mathrm{i}$ and $\mathrm{j}$ clusters in Equation 2 and max is the maximum distance between the elements in $\mathrm{k}$ clusters. The distance between the main objective clusters of the Dunn index is the smallest, and the closest which are the largest cluster distances. Clustering with the largest DI will give the best clustering.

SOMs are often the preferred methods in recent years for the purpose of extracting bibliographic topology [15]. 


\subsection{Clustering with SOM Method}

The variables considered for clustering in this study are "Network structure", "Optimization Model", "Objective function", "Methods to Handle Uncertainty" and "Solution approach".

Thevaluesforthesevariablesaredefined as follows:

1. Network Structure:

- OLSC (Open-loopsupplychain),

- CLSC (Closed-loopsupplychain)

2. Optimization Model:

- LP (Linear Programming),

- NLP (Nonlinear Programming),

- MILP (Mixed IntegerLinear Programming),

- MINLP (Mixed IntegerNonlinear Programming)

3. Objective Function:

- Singleobjective,

- Multi-objective

4. Methods to Handle Uncertainty:

- SA (Sensitivity Analysis),

- Scenario Analysis,
- StochasticOptimization,

- Fuzzy

5.Solution Approach:

- E (Exact),

- $\mathrm{H}$ (Heuristic),

- M-H (Meta- Heuristic)

Thevariablesused in the study are categorical values, where each variable can attain one of binary values, $0-1$. For example, if OLSC has a value of "0", it means "the network structure of the problem is not designed as an open loop supply chain". Inthiscase, a total of 15 variables $0-1$ values are used for the network structure.

Let us illustrate the structure of an input vector by an example. Harraz and Galal (2011) have tried to design a multi-objective sustainable recycling network for vehicles that have completed their lifetime in Egypt. Designed as openloop, the network is modeled as mixed integer linear programming (MILP) problem and uncertainties in the operation are not considered. The problem was solved using exact solution approach.

Variables used in the operation of Harraz and Galal will take the values shown in Table 2 in line with the given description above..

Table 2: The representation of variables

\begin{tabular}{|c|c|c|c|c|c|c|c|c|c|c|c|c|c|c|}
\hline \multicolumn{2}{|c|}{$\begin{array}{l}\text { Network } \\
\text { Structure } \\
\end{array}$} & \multicolumn{4}{|c|}{ Optimization Model } & \multicolumn{2}{|c|}{$\begin{array}{l}\text { Objective } \\
\text { Function } \\
\end{array}$} & \multicolumn{4}{|c|}{ Methods to handle uncertainty } & \multicolumn{3}{|c|}{$\begin{array}{l}\text { Solution } \\
\text { Method }\end{array}$} \\
\hline OLSC & CLSC & LP & NLP & MILP & MINLP & Single & Multi & SA & Scenario & Stochastic & Fuzzy & E & & M-H \\
\hline 1 & 0 & 0 & 0 & 1 & 0 & 0 & 1 & 0 & 0 & 0 & 0 & 1 & & 0 \\
\hline
\end{tabular}

In this study, ELV's reverse logistics network design that has been benefited from 23 articles published since 2005. In the clustering analysis of the relevant articles, it is expected that the number of clusters will be around 2,3 (23 $* 10 \%$ ) and around 4,8 (square root of sample size) compared to other approaches [15]. For this purpose, all two-dimensional topologies have been investitaged with cluster numbers between 2 to 5 , namely $1 \times 2,1 \times 3,1 \times 4$, $1 \times 5,2 \times 1$ and $2 \times 2$ topologies. For the topologies considered, the DI was calculated to be able to assess the validityof each topology.

As stated in Section 2.2, the weights are randomly initialized while clustering a data with SOM. To eliminate the random effects on topology selection process, 30 independent experiments were conducted and averages of DIs of each candidate topology over 30 trials were compared.

According to the DI results shown in Figure 1, 1x3 topology has a higher value, which leads to better clustering.

Detailed information on the 23 studies on the "Reverse Logistics Network Design" on ELVs usedare given in Table 3.

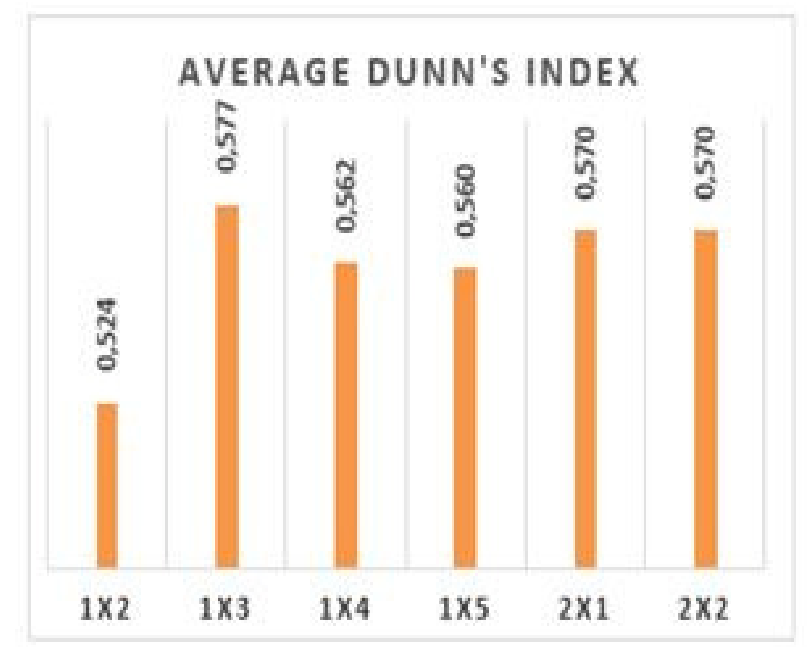

Figure 1. Average Dunn Indeces for each SOM topology 
35 E. Cin, A.O. Kusakci / Southeast Europe Journal of Soft Computing Vol.6 No.1 March 2017 (32-39)

Table 3: Summary of Lietrature survey on Reverse logistics network design of ELVs

\begin{tabular}{|c|c|c|c|c|c|c|c|c|c|c|c|c|c|c|c|c|}
\hline \multirow[b]{3}{*}{ References } & \multirow[b]{3}{*}{ Year } & \multirow{2}{*}{\multicolumn{2}{|c|}{$\begin{array}{l}\text { Network } \\
\text { Structure }\end{array}$}} & \multicolumn{10}{|c|}{ Modeling Technique } & \multirow{2}{*}{\multicolumn{3}{|c|}{$\begin{array}{l}\text { Solution } \\
\text { Approach }\end{array}$}} \\
\hline & & & & \multicolumn{4}{|c|}{ Model } & \multicolumn{2}{|c|}{ Objective F. } & \multicolumn{4}{|c|}{ Methods to handle uncertainty } & & & \\
\hline & & OLSC & CLSC & $\mathbf{L P}$ & NLP & MILP & MINLP & Single & Multi & SA & Scenario & Stochastic & Fuzzy & $\mathbf{E}$ & $\mathbf{H}$ & M-H \\
\hline Choi et al.[16] & 2005 & $\sqrt{ }$ & & & & $\sqrt{ }$ & & $\sqrt{ }$ & & $\sqrt{ }$ & $\sqrt{ }$ & & & $\sqrt{ }$ & & \\
\hline Schultmann et al.[17] & 2006 & & $\sqrt{ }$ & & & & $\sqrt{ }$ & $\sqrt{ }$ & & & $\sqrt{ }$ & & & & $\sqrt{ }$ & \\
\hline Mansour\&Zarei[18] & 2008 & $\sqrt{ }$ & & & & $\sqrt{ }$ & & $\sqrt{ }$ & & & $\sqrt{ }$ & & & & $\sqrt{ }$ & \\
\hline Xiaolong et al.[19] & 2009 & & $\sqrt{ }$ & & & $\sqrt{ }$ & & $\sqrt{ }$ & & & $\sqrt{ }$ & & & $\sqrt{ }$ & & \\
\hline Cruz-Rivera\&Ertel[20] & 2009 & & $\sqrt{ }$ & & & $\sqrt{ }$ & & $\sqrt{ }$ & & & $\sqrt{ }$ & & & $\sqrt{ }$ & & \\
\hline $\begin{array}{l}\text { Mahmoudzadeh et } \\
\text { al.[21] }\end{array}$ & 2009 & $\sqrt{ }$ & & & & $\sqrt{ }$ & & $\sqrt{ }$ & & $\sqrt{ }$ & & & & $\sqrt{ }$ & & \\
\hline Mansour et al.[22] & 2010 & $\sqrt{ }$ & & & & $\sqrt{ }$ & & $\sqrt{ }$ & & & $\sqrt{ }$ & & & & & $\sqrt{ }$ \\
\hline Harraz\&Galal[23] & 2011 & $\sqrt{ }$ & & & & $\sqrt{ }$ & & & $\sqrt{ }$ & & & & & $\sqrt{ }$ & & \\
\hline $\begin{array}{l}\text { Mahmoudzadeh et } \\
\text { al.[24] }\end{array}$ & 2011 & $\sqrt{ }$ & & & & $\sqrt{ }$ & & $\sqrt{ }$ & & $\sqrt{ }$ & & & & $\sqrt{ }$ & & \\
\hline $\begin{array}{l}\text { A. Merkisz- } \\
\text { Guranowska[25] }\end{array}$ & 2011 & $\sqrt{ }$ & & & & $\sqrt{ }$ & & $\sqrt{ }$ & & & & & & & $\sqrt{ }$ & \\
\hline $\begin{array}{l}\text { A. Merkisz- } \\
\text { Guranowska[26] }\end{array}$ & 2011 & $\sqrt{ }$ & & & & $\sqrt{ }$ & & $\sqrt{ }$ & & & & & & & $\sqrt{ }$ & \\
\hline Niziplioğlu[27] & 2012 & $\sqrt{ }$ & & & & $\sqrt{ }$ & & $\sqrt{ }$ & & & $\sqrt{ }$ & & & $\sqrt{ }$ & & \\
\hline Simic\&Dimitrijević[28] & 2012 & $\sqrt{ }$ & & $\sqrt{ }$ & & & & $\sqrt{ }$ & & $\sqrt{ }$ & $\sqrt{ }$ & & & $\sqrt{ }$ & & \\
\hline Gołębiewski et al.[29] & 2013 & & $\sqrt{ }$ & & & & $\sqrt{ }$ & $\sqrt{ }$ & & $\sqrt{ }$ & & & & & & $\sqrt{ }$ \\
\hline Simic\&Dimitrijević[30] & 2013 & $\sqrt{ }$ & & & & $\sqrt{ }$ & & & $\sqrt{ }$ & $\sqrt{ }$ & $\sqrt{ }$ & & & $\sqrt{ }$ & & \\
\hline Ene \& Öztürk[31] & 2014 & $\sqrt{ }$ & & & & $\sqrt{ }$ & & $\sqrt{ }$ & & & & & & & & $\sqrt{ }$ \\
\hline Simic\&Dimitrijević[32] & 2015 & $\sqrt{ }$ & & $\sqrt{ }$ & & & & $\sqrt{ }$ & & & $\sqrt{ }$ & & & $\sqrt{ }$ & & \\
\hline Ene \& Öztürk[33] & 2015 & $\sqrt{ }$ & & & & $\sqrt{ }$ & & $\sqrt{ }$ & & $\sqrt{ }$ & $\sqrt{ }$ & & & $\sqrt{ }$ & & \\
\hline Simic[34] & 2015 & $\sqrt{ }$ & & $\sqrt{ }$ & & & & $\sqrt{ }$ & & & $\sqrt{ }$ & & $\sqrt{ }$ & $\sqrt{ }$ & & $\sqrt{ }$ \\
\hline Demirel et al.[35] & 2016 & $\sqrt{ }$ & & & & $\sqrt{ }$ & & $\sqrt{ }$ & & & $\sqrt{ }$ & & & $\sqrt{ }$ & & \\
\hline Phuc et al.[36] & 2016 & $\sqrt{ }$ & & & & $\sqrt{ }$ & & $\sqrt{ }$ & & & & & $\sqrt{ }$ & $\sqrt{ }$ & & \\
\hline Srinivasan\&Khan[37] & 2016 & & $\sqrt{ }$ & & & $\sqrt{ }$ & & & $\sqrt{ }$ & $\sqrt{ }$ & $\sqrt{ }$ & & & $\sqrt{ }$ & & \\
\hline Özceylan et al.[38] & 2017 & & $\sqrt{ }$ & $\sqrt{ }$ & & & & & $\sqrt{ }$ & & $\sqrt{ }$ & & & $\sqrt{ }$ & & \\
\hline
\end{tabular}

\subsection{Clustering results}

The best topology we identified is $1 \times 3$ topology among the examined topologies. Figure 2 shows the topology giving the best clustering and the number of runs in each cluster.The scientific works falling into each cluster are given in Table 4 along with the years in which the work was done.

Table 5 shows the average values of each cluster based on the variables, according to the topology giving the best cluster. By examining these values, it is possible to find inferences for the characteristics of each cohort.

The majority of the work in Cluster $\mathbf{1}$ is designed as an open-loop chain and is modeled according to mixed integer linear programming. In small number of studies, a closed-loop chain was used as the network structure and a mixed integer programming was used as the model. The most important feature that differentiates these studies from other clusters is the use of heuristic methods in the solution of the model. Scenario analyzsis has been included in almost half of the studies to deal with the uncertainties in the model. In addition to scenario analysis, sensitivity analysis was used in a small number of studies.

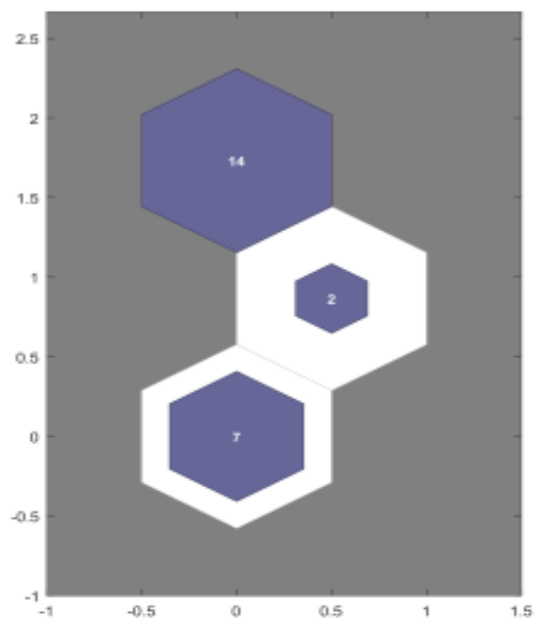

Figure 2. 1x3 topology structure and element counts of clusters 
36 E. Cin, A.O. Kusakci / Southeast Europe Journal of Soft Computing Vol.6 No.1 March 2017 (32-39)

Table 4: Elements of clusters in 1x3 topology.

\begin{tabular}{|c|c|}
\hline \multicolumn{2}{|c|}{ Cluster 1} \\
\hline Author & Year \\
\hline Schultmann et al. & 2006 \\
\hline Mansour \&Zarei & 2008 \\
\hline Mansour et al. & 2010 \\
\hline Merkisz-Guranowska & 2011 \\
\hline Merkisz-Guranowska & 2011 \\
\hline Gołębiewski et al. & 2013 \\
\hline Ene\&Öztürk & 2014 \\
\hline
\end{tabular}

\begin{tabular}{|c|c|}
\hline \multicolumn{2}{|c|}{ Cluster 2} \\
\hline Author & Year \\
\hline Srinivasan \& Khan & 2016 \\
\hline Özceylan et al. & 2017 \\
\hline
\end{tabular}

\begin{tabular}{|c|c|}
\hline \multicolumn{2}{|c|}{ Cluster 3} \\
\hline Author & Year \\
\hline Choi et al. & 2005 \\
\hline Xiaolong et al. & 2009 \\
\hline Cruz-Rivera \&Ertel & 2009 \\
\hline Mahmoudzadeh et al. & 2009 \\
\hline Harraz\&Galal & 2011 \\
\hline Mahmoudzadeh et al. & 2011 \\
\hline Niziplioğlu & 2012 \\
\hline Simic\&Dimitrijević & 2012 \\
\hline Simic\&Dimitrijević & 2013 \\
\hline Simic\&Dimitrijević & 2015 \\
\hline Ene\&Öztürk & 2015 \\
\hline Simic (Waste management) & 2015 \\
\hline Demirel et al. & 2016 \\
\hline Phuc et al. & 2016 \\
\hline
\end{tabular}

The most important feature that separates the studies in Cluster 2 from the other clusters is that all of the studies are designed as closed-loop chains and are multi-objective. Problems were modeled as linear programming and mixed integer linear programming problems and solved through Exact methods. The studies also included scenarios and sensitivity analysis for eliminating uncertainties.

The majority of the work in Cluster $\mathbf{3}$ was designed as an open-loop supply chain and modeled according to mixed integer linear programming. In a small number of studies, a closed-loop supply chain was used as network structure and linear programming was used as a model. The most important feature that differentiates these studies from other clusters is that fuzzy methods are used to resolve ambiguities, unlike scenario and sensitivity analysis. All of the studies in the cluster are single objective models and are resolved through exact methods

Figure 3, shows a weight plane for each element of the input vector. They are visualizations of the weights that connect each input to each of the neurons where the most negative connections shown as blue, zero connections as black, and the strongest positive connections as red. If the connection patterns of two inputs are very similar, you can assume that the inputs are highly correlated. More precisely, figure 3 is another way of expressing the nature of relations between each input and each cluster.

\section{Evaluation of the Clustered Studies}

In Cluster 1, the presence of reverse logistic network design models solved with heuristic and meta-heuristic methods is the most important feature that distinguishes this cluster from the other clusters. While most of the work in this chapter is designed as an open loop network, a small part is designed as a closed loop logistic chain.

All networks designed as open loop logistic chains are modeled with mixed integer linear programming to minimize installation and transport costs. Within the cluster, there are works solved by methods such as Priority-based genetic algorithm ([31]) for reasons such as complexity of models and variable number, Genetic algorithm ([22];[25]), Evolutionary algorithm ([26]), multiple initialization algorithms ([18]).

Networks designed as closed loop chains in the cluster are modeled according to mixed integer nonlinear programming. Studies aiming at cost minimization include studies of vehicle rotations ([17]) for reverse logistics (RL) networks and attempts to develop an optimal model that will determine the location of elements in the network, and the use of genetic algorithms ([29]) in the solution due to the high complexity of the model.

Table 5:Average values of the variables for each cluster according to the $1 \times 3$ topology

\begin{tabular}{|c|c|c|c|c|c|c|c|c|c|c|c|c|c|c|c|}
\hline \multirow[t]{2}{*}{ NODE } & \multicolumn{2}{|c|}{$\begin{array}{l}\text { Network } \\
\text { Structure }\end{array}$} & \multicolumn{4}{|c|}{ Model } & \multicolumn{2}{|c|}{$\begin{array}{l}\text { Objective } \\
\text { Function }\end{array}$} & \multicolumn{4}{|c|}{ Methods to handle uncertainty } & \multicolumn{3}{|c|}{$\begin{array}{l}\text { Solution } \\
\text { Method }\end{array}$} \\
\hline & OLSC & CLSC & LP & NLP & MILP & MINLP & Single & Multi & SA & Scenario & Stoc. & Fuzzy & $\mathrm{E}$ & $\mathrm{H}$ & M-H \\
\hline $\operatorname{NODE}(1,1)$ & 0,71 & 0,28 & 0 & 0 & 0,71 & 0,29 & 1 & 0 & 0,14 & 0,43 & 0 & 0 & 0 & 0,57 & 0,43 \\
\hline $\operatorname{NODE}(1,2)$ & 0 & 1 & 0,5 & 0 & 0,5 & 0 & 0 & 1 & 0,5 & 1 & 0 & 0 & 1 & 0 & 0 \\
\hline NODE $(1,3)$ & 0,86 & 0,14 & 0,2 & 0 & 0,78 & 0 & 0,86 & 0,14 & 0,36 & 0,64 & 0 & 0,14 & 1 & 0 & 0,07 \\
\hline
\end{tabular}




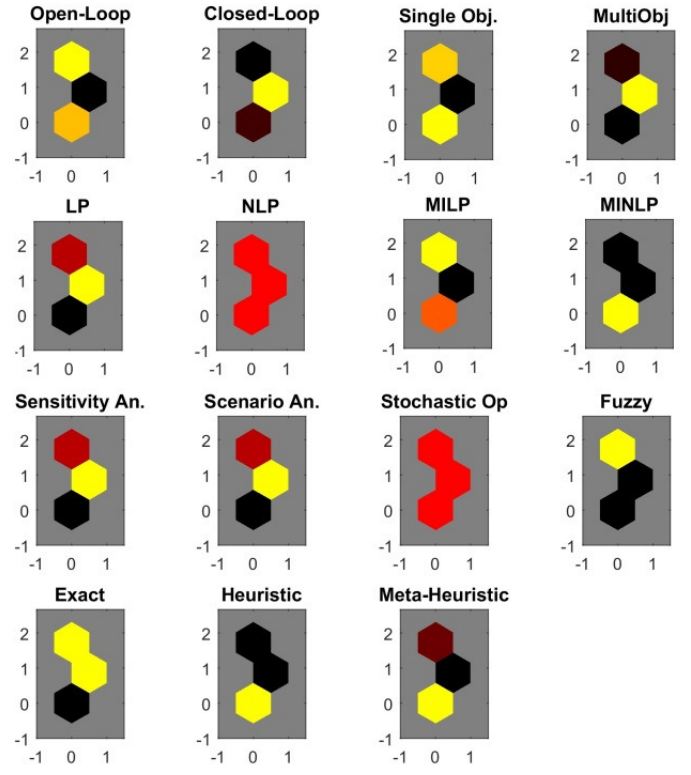

Figure 3. Weights of inputs for clusters obtained by $1 \mathrm{x} 3$ topology

Works in cluster 2 are designed as a closed loop supply chain, all of which are multi-objective. Srinivasan and Khan (2016) have worked on a multiperiod, multi-product and multi-purpose closed loop green supply chain (CLGSC) network. It is optimized using the network target programming approach modeled by mixed integer linear programming (MILP). The aim of the work is to minimize the total cost and total emissions in the supply chain. Özceylan (2017) tried to optimize the total cost of networking and the allocation of materials between network components as linear programming in their work.

The most important feature is that separates the studies in Cluster 3 from other studies which are the use of fuzzy methods ([36]; [32]) in eliminating ambiguities. Phuc (2016) tried to solve the reverse logistics network design for ELV with a model which minimizes the total cost of the entire network (including installation, handling and processing costs). Because some parameters in the model are ambiguous, they used fuzzy linear programming and possible mixed integer linear programming methods together. Simic and Dimitrijevic (2015) have attempted to develop a model that takes uncertainty into account for optimal long-term planning in Serbian vehicle recycling plants. Interval linear programming (ILP) approach is used to formulate the model in scenario analyzes and fuzzy methods.

There are reverse logistics network design studies modelled as closed loop ([20]; [19]) within the cluster. Xiaolong et al. (2009) addressed the problem of location selection of the ELV reverse logistics network within closed loop supply chains. Mixed integer programming model has developed for ELV the reverse logistics network. Cruz-Rivera and Ertel (2009) have dealt with a closed-loop supply chain network design for vehicles that have completed their lifetime in their work. The network design is modeled as a plant location problem with no capacity.

The studies within the cluster are generally single objective ([16];[28]; [33]) and aim to maximize profit or minimize cost ([21];[24];[27]; [35]). Choi et al. (2005) dealt with a real recycling problem in their work for which maximization of profit was aimed at. Simic and Dimitrijevic (2012) addressed the problem of production planning in the recycling facilities of completed vehicles in Europe in their work. The problem is formulated using a linear programming model in the direction of profit maximization. Ene and Öztürk (2015) aimed to maximize revenue in product operations of vehicles that have completed their lives and to reduce pollution. Mahmoudzadeh et al. (2009) proposed a model that includes 3rd Party Logistics (3PL) for the recycling of vehicles that have completed their lifetime in their work. The problem that they aim to minimize the total cost of the network is modeled on a capacitive plant location budget. Niziplioğlu (2012) tried to create a model that minimizes the recovery cost of vehicles that have completed their life in Turkey. Demirel et al. (2016) included a case study in which they focused on reverse logistics network design for ELVs in Ankara, the capital of Turkey, and aimed at cost minimization.

There are multi-objective reverse ([23];[30]) logistics studies in the cluster as well as single-objective studies. Harraz and Galal (2011) have tried to present a sustainable recycling network design for vehicles that have completed their lifetime in Egypt. A mixed integer goal programming model is proposed for multi-objective network design. Simic and Dimitrijevic (2013) have developed a clear range of linear programming models to meet ecoefficiency quotas in EU vehicle recycling plants, maximize system profits, minimize decision risk, fill defined research gaps, and optimize long-term planning.

\section{RESULTS}

ELVs are very important sources of economic value due to recyclable and reusable materials that actually contain the harmful environmental effects. In recent years, environmental awareness / consumer awareness, public sanctions and legislation have led to increasingly important research into the recycling of ELVs. In this study, works related to logistics networks and modeling are discussed in context of ELV. 23 scientific works between 2005 and 2017 are studied and distribution of reverse logistics network design works performed for ELV were determined by cluster analysis conducted with SOM.

Themostimportantinformationarises in clustering is that the problem of ELV recycling is usually single-objective and cost minimization is targeted. For the studies examined, only a few studies aimed profit maximization and multi-objective models. Furthermore, clustering analysis shows that open loop network designs have been intensivly studied. It is observed that mixed integer formulations are mostly used as a model and nononlinear programming approach is implemented. In the solutions of 
38 E. Cin, A.O. Kusakci / Southeast Europe Journal of Soft Computing Vol.6 No.1 March 2017 (32-39)

the problems that are handled, exact methods are preferred. Recently, fuzzy methods have begun to be preferred, while sensitivity and scenario analysis are the most used for dealing with uncertainty. But, still, there is a lack of diversity in terms of uncertainty handling. Thus, new attampts in this domain mayfocus on thisgap.

The researchers are expected to take advantage of such topology studies when they determine the criteria they will deal with, the model, and the method to be used. For this reason, this study will be of great importance for researchers focusing on logistics netwrok design on ELV.

\section{REFERENCES}

[1] L. Kaufman and P. J. Rousseeuw, Finding Groups in Data: An Introduction to Cluster Analysis (Wiley Series in Probability and Statistics). 1990.

[2] J. B. MacQueen, "Some Methods for classification and Analysis of Multivariate Observations," in Proceedings of 5-th Berkeley Symposium on Mathematical Statistics and Probability, 1967, vol. 1, pp. 281-297.

[3] F. Höppner, "Speeding up fuzzy c-means: using a hierarchical data organisation to control the precision of membership calculation," Fuzzy Sets Syst., vol. 128, no. 3, pp. 365-376, Jun. 2002.

[4] T. Kohonen, "Self-organized formation of topologically correct feature maps," Biol. Cybern., vol. 43, no. 1, pp. 59-69, 1982.

[5] A. Oğuzlar, "Kümeleme Analizinde Yeni Bir Yaklaşim: Kendini Düzenleyen Haritalar (Kohonen Ağlari)," İktisadi ve İdari Bilim. Derg., vol. 19-2, 2005.

[6] M. Y. Kiang, "Extending the Kohonen selforganizing map networks for clustering analysis," Comput. Stat. Data Anal., vol. 38, no. 2, pp. 161180, 2001.

[7] T. Reutterer, "Competitive Market Structure and Segmentation Analysis with Self-Organizing Feature Maps," Proc. 27th EMAC Conf., pp. 85115, 1998.

[8] C. Budayan, "Strategic Group Analysis: Strategic perspective, differentiation and performance in construction," no. July, pp. 1-289, 2008.

[9] S. S. Haykin, Neural networks and learning machines, 3rd Edition. 2009.

[10] T. Kohonen, Self-Organizing Maps, vol. 30. 2001.

[11] L. Folguera, J. Zupan, D. Cicerone, and J. F. Magallanes, "Self-organizing maps for imputation of missing data in incomplete data matrices," Chemom. Intell. Lab. Syst., 2015.

[12] C. C. Hsu, "Generalizing self-organizing map for categorical data," IEEE Trans. Neural Networks, vol. 17 , no. 2, pp. 294-304, 2006.

[13] M. Özçalıc1, "Clustering Stocks with Selforganizing Maps: An application on Stocks Listed in BIST50 Index," Istanbul Univ. J. Sch. Bus., vol.
45, pp. 22-33, 2016.

[14] A. T. Azar, S. A. El-Said, and A. E. Hassanien, "Fuzzy and hard clustering analysis for thyroid disease," Comput. Methods Programs Biomed., vol. 111, no. 1, pp. 1-16, 2013.

[15] S. Ercan and G. Kayakutlu, "SCHEDULING IN ENERGY SYSTEMS," Sigma J. Eng. Nat. Sci., pp. 679-690, 2015.

[16] J. Choi, J. A. Stuart, and K. Ramani, "Modeling of Automotive Recycling Planning in the United States," vol. 6, no. 4, 2005.

[17] F. Schultmann, M. Zumkeller, and O. Rentz, "Modeling reverse logistic tasks within closedloop supply chains: An example from the automotive industry," in European Journal of Operational Research, 2006.

[18] S. Mansour and M. Zarei, "A multi-period reverse logistics optimisation model for end-of-life vehicles recovery based on EU Directive."

[19] J. Xiaolong, F. Rui, and L. WANG, "The Location Selection of Automobile Reverse Logistics Network within Closed-loop Supply Chains," Sch. Automob. Chang. Univ., vol. 75, 209AD.

[20] R. Cruz-Rivera and J. Ertel, "Reverse logistics network design for the collection of End-of-Life Vehicles in Mexico," Eur. J. Oper. Res., 2009.

[21] M. Mahmoudzadeh, S. Mansour, S. Shokoohyar, and B. Karimi, "Designing and Modelling a Third Party Reverse Logistics Network for End of Life Vehicles," 2009.

[22] S. Mansour, M. Zarei, A. Husseinzadeh Kashan, and B. Karimi, "Designing a reverse logistics network for end-of-life vehicles recovery," Math. Probl. Eng., 2010.

[23] N. A. Harraz and N. M. Galal, "Design of Sustainable End-of-life Vehicle recovery network in Egypt," Ain Shams Eng. J., 2011.

[24] M. Mahmoudzadeh, S. Mansour, and B. Karimi, "A Decentralized Reverse Logistics Network for End of Life Vehicles from Third Party Provider Perspective," 2nd Int. Conf. Environ. Sci. Technol., vol. 2, pp. 338-342, 2011.

[25] A. Merkisz-Guranowska, "End-Of-Life Vehicles Recycling Network Design," J. KONES Powertrain Transp., vol. 18, no. 3, 2011.

[26] A. Merkisz-Guranowska, "The optimization of vehicles recycling facility location," in WIT Transactions on the Built Environment, 2011.

[27] M. Niziplioğlu, "End Of Life Vehicles Management In Turkey," 2012.

[28] V. Simic and B. Dimitrijevic, "Modelling production processes in a vehicle recycling plant.," Waste Manag. Res., vol. 30, no. 9, pp. 940-8, 2012.

[29] B. Gołębiewski, J. Trajer, M. Jaros, and R. Winiczenko, "Modelling of the location of vehicle recycling facilities: A case study in Poland," Resour. Conserv. Recycl., vol. 80, no. 1, pp. 10 20, 2013. 
39 E. Cin, A.O. Kusakci / Southeast Europe Journal of Soft Computing Vol.6 No.1 March 2017 (32-39)

[30] V. Simic and B. Dimitrijevic, "Risk explicit interval linear programming model for long-term planning of vehicle recycling in the EU legislative context under uncertainty," Resour. Conserv. Recycl., 2013.

[31] S. Ene and N. Öztürk, "Ömrünü Tamamlamış Araçlar İçin Toplama Ağının Tasarımı," in OTEKON'14 7. Otomotiv Teknolojileri Kongresi, 2014, pp. 1-7.

[32] V. Simic and B. Dimitrijević, "End-Of-Life Vehicle Recycling In The Republic Of Serbia: Interval Linear Programming Model For LongTerm Planning Under Uncertainty," in 1st Logistics International Conference Belgrade, Serbia, 2015, pp. 252-257.

[33] S. Ene and N. Öztürk, "Network modeling for reverse flows of end-of-life vehicles," Waste Manag., vol. 38, no. 1, pp. 284-296, 2015.

[34] V. Simic, "Fuzzy risk explicit interval linear programming model for end-of-life vehicle recycling planning in the EU," 2015.

[35] E. Demirel, N. Demirel, and H. Gökçen, “A mixed integer linear programming model to optimize reverse logistics activities of end-of-life vehicles in Turkey," J. Clean. Prod., vol. 112, no. January 2011, pp. 2101-2113, 2016.

[36] P. Nguyen, K. Phuc, V. F. Yu, and Y.-C. Tsao, "Optimizing fuzzy reverse supply chain for endof-life vehicles," 2016.

[37] S. Srinivasan and S. H. Khan, "Environmentally Conscious Optimization of Closed Loop Supply Chain Network with Vehicle Routing," vol. 11, no. 3, pp. 223-243, 2016.

[38] E. Özceylan, N. Demirel, C. Çetinkaya, and E. Demirel, "A Closed-Loop Supply Chain Network Design for Automotive Industry in Turkey," Comput. Ind. Eng., 2016. 